\title{
QTAIM and ELF topological analyses of zinc-amido complexes
}

\author{
Christine Lepetit ${ }^{1} \cdot$ Myrtil L. Kahn $^{1}$
}

\begin{abstract}
The structures of three dinuclear zinc-amido complexes, involved in the very first step of the preparation of zinc oxide nanoparticles via an organometallic route, have been investigated by density functional theory computational studies. The various zinc-nitrogen and zinc-cyclohexyl bonds are finely characterized using quantum theory of atoms in molecules and electron localization function (ELF) topological analyses. The results are compared to the topological analyses of parent zinc-amido or zinc-alkyl complexes, for which an experimental structure has been already reported. The original two-component dative zinc-amido bond is unravelled by ELF topological analysis. Fukui indices condensed on the ELF basins allow for the comparison of the chemical reactivity of the three dinuclear zinc-amido complexes. The larger sensitivity to electrophilic attack of the terminal zinc-amido bonds with respect to the bridging intracyclic zinc-amido bonds or with respect to the terminal zinc-cyclohexyl bonds is evidenced.
\end{abstract}

Keywords Zinc-amido bond · Topological analyses · QTAIM · ELF · Fukui indices

\section{Introduction}

The synthesis of zinc oxide nanoparticles using an organometallic approach was developed in our team in the early 2000s [1]. This approach consists in the controlled hydrolysis of an organometallic precursor in the presence of ligands allowing a control of the size and shape of the nanoparticles, typically long-chain aliphatic carboxylic acids and/or amines. Recently, we have shown the essential role of the mixing time between the organometallic precursor usually used, namely dicyclohexyl zinc $\left(\mathrm{Zncy}_{2}\right)$ and a primary amine such as dodecylamine (DDA, $\mathrm{C}_{12} \mathrm{H}_{25} \mathrm{NH}_{2}$ ). In the

This manuscript is dedicated to, and in memory of, the late Prof Michel Che.

Christine Lepetit

christine.lepetit@1cc-toulouse.fr

1 LCC-CNRS, Université de Toulouse, CNRS, Toulouse, France 
course of time, a gel is formed. This influences the size and shape of the resulting nanoparticles. An oligomerization mechanism involving an acid-base reaction has been proposed for the formation of this gel [2].

To go further, it is important to understand each elementary step in the process of nanoparticle formation. This requires a detailed understanding of the reactivity of the precursors. Early NMR spectra suggest the formation of oligomeric structures through the de-protonation of the amine to an amido ligand, which is able to bridge two zinc centres via dative bonding, yielding dicyclohexyl-amido-zinc oligomers of increasing size via a polycondensation reaction (Fig. 1) [2]. The structure of the first oligomer representatives (di- and tetranuclear) has been investigated by density functional theory (DFT) computational studies (PBE-D3/DGDZVP level), and a possible polymerization pathway was proposed on the basis of energy stabilization calculations. Using the calculated structure of the tetranuclear oligomer model and the Debbye's formula, a wide-angle X-ray scattering (WAXS) radial distribution function (RDF) in good agreement with the experimental WAXS signatures was simulated, supporting the formation of such oligomeric species before cross-linking [2].

In this work, the chemical bonding in three dinuclear zinc-amido complexes formed in the very first steps of the oligomerization will be finely characterized using quantum theory of atoms in molecules (QTAIM) [3, 4] and electron localization function (ELF) [5, 6] topological analyses. The latter topological analyses have been shown to be unique theoretical tools for chemical bonding analysis [7, 8]. The studies will focus on $\mathrm{Zn}-\mathrm{N}$ and $\mathrm{Zn}$-alkyl bonds, in comparison with ELF and QTAIM topological analyses of known zinc-amido or zinc-amino complexes, for which an experimental structure has been reported in the literature.

Among the chemical reactivity descriptors of the conceptual DFT, Fukui functions are suitable for probing soft sites of reactants that are involved in orbital-controlled interactions with electrophiles, nucleophiles or radicals [9]. The Fukui function was indeed introduced by Parr and Yang, as the response of the electron density of the molecular system to a change in the global number of electrons [10]. In this work, frontier molecular orbital (FMO) Fukui functions $f_{\mathrm{X}}(\mathrm{r})$ (in which the electron density is approximated by densities of the FMOs) condensed on QTAIM [11] or ELF [12] topological partitions have therefore been calculated to investigate the chemical reactivity of the zinc-amido complexes of this work. $f^{a} X(r)=\int_{X}\left|f_{K S}^{F}(r)\right|^{2} \mathrm{~d} r$ is the contribution of the FMO $\mathrm{F}$ $(a=-: F=\mathrm{HOMO} ; a=+: F=\mathrm{LUMO})$ to the atomic QTAIM basin or to the core or valence ELF basin $X$. These Fukui indices are confined into the $0-1$ range,

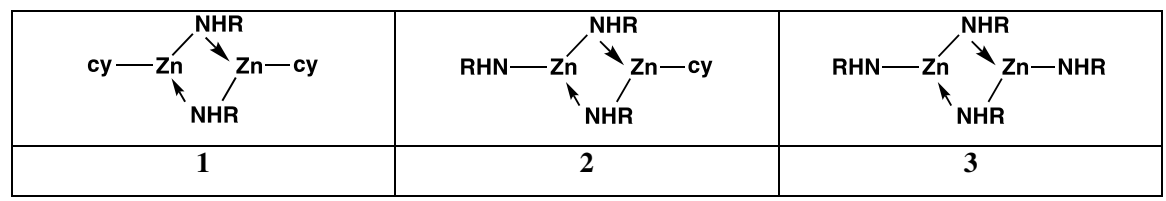

Fig. 1 Structures of the three dinuclear amidocyclohexylzinc model complexes studied in this work using topological analyses $\left(\mathrm{R}=\mathrm{C}_{6} \mathrm{H}_{13}\right.$ for the hexylamine model of DDA) 
and they sum up to one. The larger the value of the $f$ index, the more reactive the corresponding basin $X$.

The Fukui indices condensed on the ELF basins will be calculated for the three dinuclear zinc-amido complexes studied here, in order to compare the chemical reactivity of the terminal zinc-amino bonds with respect to the one of the bridging zinc-amido bonds or to the terminal zinc-alkyl bonds.

\section{Results and discussion}

The oligomerization pathway involves various steps related either to (i) an acid-base reaction between the cyclohexyl ligand and the amine (Eq. 1, Scheme 1), or (ii) a dimerization via the formation of two bridging dative bonds between the amido ligands and two Zn centres [2]. Equations 2-4 (Scheme 1) illustrate the formation of the first oligomer representatives, namely the dinuclear amidocyclohexylzinc complexes 1-3 (Fig. 1).

In order to help for the assignment of the results, the topological descriptors of model complexes 1-3 will be compared to the ones of parent zinc-amido complexes referred to as PAHVUP [13] and CADCEP [14] in the Cambridge database (CDB), from which their experimental structure was extracted (Fig. 2). These complexes were previously used for the calibration of the DFT calculation level suitable for the description of Zn-amido oligomers [2]. Similarly, the ELF and QTAIM topological analyses of the experimental structure of diethylzinc $\left(\mathrm{ZnEt}_{2}\right)$ [15] and of the DFTcalculated structure of dicyclohexylzinc $\left(\mathrm{Zncy}_{2}\right)$ were performed in order to be used as standard for comparison with the $\mathrm{Zn}-\mathrm{C}$ bonds of complexes 1-3.

Geometries of 1-3 and of $\mathrm{Zncy}_{2}$ were fully optimized at the PBE-D3/DGDZVP level of calculation (Fig. 3). This DFT calculation level was shown to be suitable for the description of such zinc-amido complexes in previous calibration studies

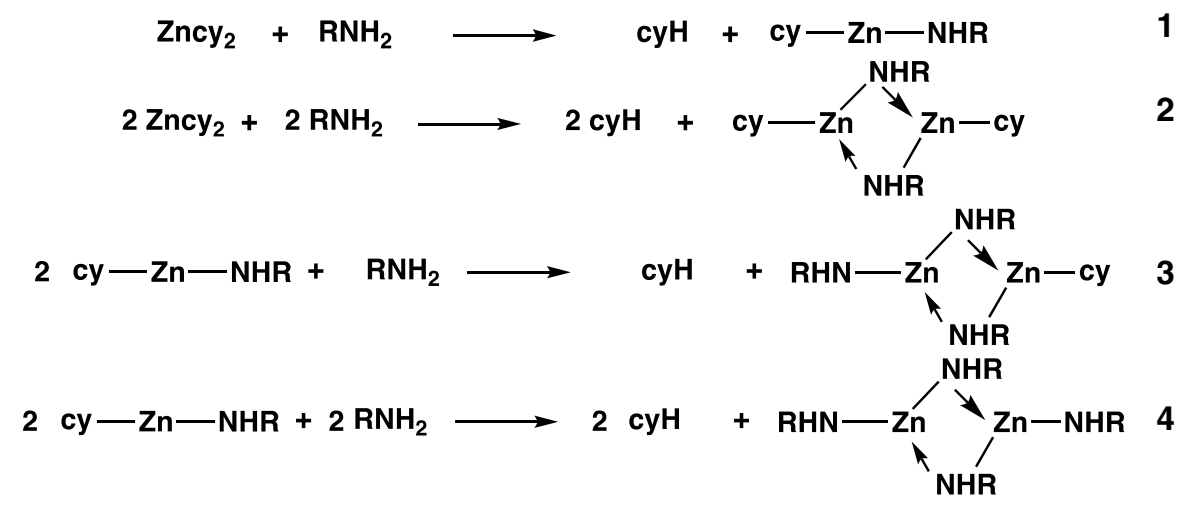

Scheme 1 Structures of dinuclear zinc complexes 1-3 (Fig. 1), resulting from the intramolecular acidbase reaction between $\mathrm{Zncy}_{2}$ and the DDA, followed by a dimerization via the formation of two bridging dative bonds [2]. $\mathrm{R}=\mathrm{C}_{12} \mathrm{H}_{25}$ for the experimental DDA or $\mathrm{R}=\mathrm{C}_{6} \mathrm{H}_{13}$ for the hexylamine model 
Fig. 2 Experimental parent zinc complexes used hereafter as references for the topological analysis assignments<smiles>CC(C)(C)N([13CH3])[Ga]N([13CH3])[14CH3]</smiles>

PAHVUP<smiles>C[Z10]1N(c2ccccc2)[Te](C)N(c2ccccc2)[Te]1c1ccccc1</smiles>

CADCEP

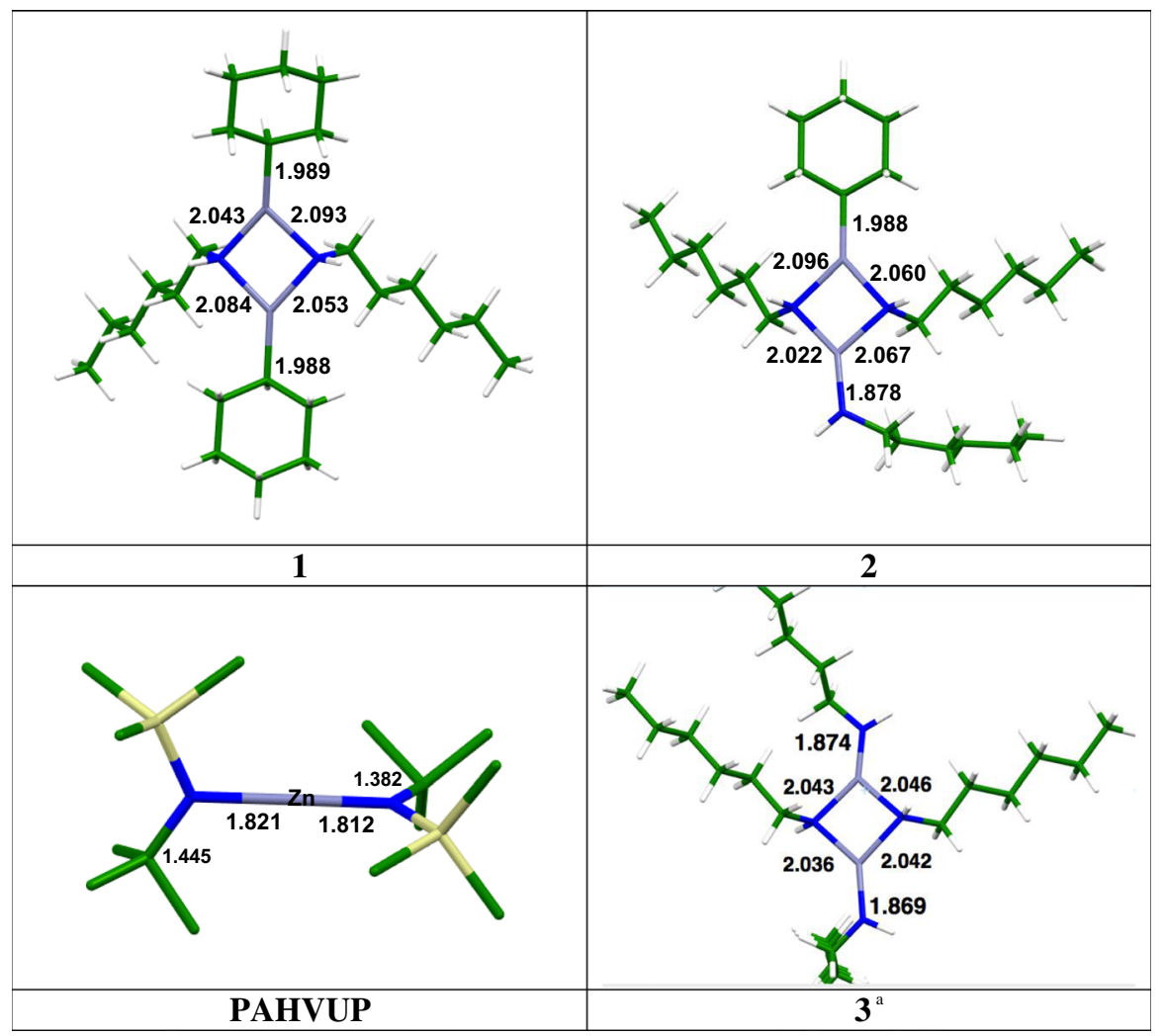

Fig. 3 Selected bond lengths (in $\AA$ ) in the calculated structures of 1-3 and PAHVUP. PBE-D3/ DGDZVP level of calculation. ${ }^{\mathrm{a} C a l c u l a t e d}$ in octylamine solvent (polarizable continuum model, $\varepsilon=3.1$ )

involving several representative experimental structures selected from the Cambridge database [2], among which the zinc complexes are PAHVUP and CADCEP (Fig. 2).

Dinuclear $\mathrm{Zn}$ complexes 1-3 exhibit an almost planar square-like $\mathrm{Zn}_{2} \mathrm{~N}_{2}$ ring, especially the structure of $\mathbf{3}$, which was calculated taking into account the octylamine solvent (polarizable continuum model, $\varepsilon \bullet=3.1$ ). Two types of $\mathrm{Zn}-\mathrm{N}$ 
bonds may be distinguished in those complexes, namely the terminal (extracyclic) $\mathrm{Zn}-\mathrm{Nt}$ bonds and the intracyclic $\mathrm{Zn}-\mathrm{Nb}$ bridging bonds.

The lengths of terminal $\mathrm{Zn}-\mathrm{Nt}$ bonds in 1-3 (about $1.87 \AA$ ) are slightly longer than both $\mathrm{Zn}-\mathrm{N}$ bond lengths in the PAHVUP zinc-amido reference extracted from CDB (about $1.81 \AA ̊$ ).

The four bridging intracyclic $\mathrm{Zn}-\mathrm{Nb}$ bonds are longer than the extracyclic $\mathrm{Zn}-\mathrm{Nt}$ bonds, but much shorter than a standard Zn-amine bond length (2.22 Å) [16]. The substitution of amido termini by one and two cyclohexyl termini reduces the symmetry of complex 3, yielding $\mathbf{2}$ and $\mathbf{1}$, respectively. In the latter complexes, the $\mathrm{Zn}-\mathrm{Nb}$ bonds adjacent to the cyclohexyl extremity are longer than the ones connected to an amido extremity (Fig. 3). Terminal Zn-Ccy bond lengths, close to $2.00 \AA$, are slightly elongated as compared to the ones in the parent $\mathrm{Zncy}_{2}$ complex calculated at the same level (1.98 $\AA$ ).

The electronic structure and chemical bonding of dinuclear zinc complexes 1-3 were further studied, using ELF and QTAIM topological analyses.

\section{ELF and QTAIM topological analyses of 3}

$\mathrm{Zn}-\mathrm{Nt}$ and $\mathrm{Zn}-\mathrm{Nb}$ bonds of $\mathbf{3}$ are first studied according to the values of their QTAIM descriptors calculated at the bond critical points (BCPs) (Table 1; Fig. 4).

The QTAIM descriptors of both terminal Zn-Nt bonds are very similar (Table 1). According to the classification of Bianchi et al. [17, 18], their $\left|\boldsymbol{V}_{\mathbf{b c p}}\right| / \boldsymbol{G}_{\mathbf{b c p}}$ ratio (1.38) refers to the intermediate bond regime $\left(1<\left|\boldsymbol{V}_{\mathbf{b c p}}\right| / G_{\mathbf{b c p}}<2\right)$ included between ionic and covalent bondings. Their significant electron density values ( $\rho_{\text {bcp }} \approx 0.12$ a.u.), large positive Laplacian values $\Delta \rho_{\mathrm{bcp}}$ and negative energy densities at the BCP $\boldsymbol{H}_{\mathrm{bcp}}$ are in favour of a dative bond (Table 1). Both DI (0.81) and $\left|\boldsymbol{H}_{\mathbf{b c p}}\right| / \boldsymbol{\rho}_{\mathbf{b c p}}(0.50)$ values suggest a significant covalence degree. According to the above criteria and to the Macchi's classification [19], the BCP descriptors of the $\mathrm{Zn}-\mathrm{Nt}$ bonds are consistent

Table 1 QTAIM descriptors (in a.u.) of the bond critical points (BCP) related to $\mathrm{Zn}-\mathrm{N}$ bonds in complex 3. B3PW91/DGDZVP level of calculation

\begin{tabular}{lllllllllll}
\hline \#BCP & BCP & $\rho_{\text {bcp }}$ & $\Delta \rho_{\text {bcp }}$ & $V_{\text {bcp }}^{\mathrm{a}}$ & $H_{\text {bcp }}^{\mathrm{b}}$ & $\left|H_{\text {bcp }}\right| / \rho_{\text {bcp }}$ & $\left|V_{\text {bcp }}\right| / G_{\text {bcp }}$ & $\mathrm{DI}^{\mathrm{c}}$ & $\begin{array}{l}\mathrm{E}_{\text {int }} \\
\left(\mathrm{kcal} \mathrm{mol}^{-1}\right)\end{array}$ \\
\hline 10 & $\mathrm{Zn}-\mathrm{Nb}$ & 0.0825 & +0.307 & -0.13228 & -0.02776 & 0.34 & 1.27 & 0.50 & 41.50 \\
12 & $\mathrm{Zn}-\mathrm{Nb}$ & 0.0834 & +0.310 & -0.13475 & -0.02858 & 0.34 & 1.27 & 0.50 & 42.28 \\
15 & $\mathrm{Zn}-\mathrm{Nb}$ & 0.0847 & +0.311 & -0.13725 & -0.02969 & 0.35 & 1.28 & 0.51 & 43.06 \\
24 & $\mathrm{Zn}-\mathrm{Nb}$ & 0.0832 & +0.306 & -0.13328 & -0.02834 & 0.34 & 1.27 & 0.50 & 41.82 \\
13 & $\mathrm{Zn}-\mathrm{Nt}$ & 0.1203 & +0.397 & -0.22354 & -0.06218 & 0.52 & 1.39 & 0.81 & 70.14 \\
25 & $\mathrm{Zn}-\mathrm{Nt}$ & 0.1191 & +0.391 & -0.21964 & -0.06094 & 0.51 & 1.38 & 0.81 & 68.91 \\
\hline
\end{tabular}

See BCP location and labelling in Fig. 4

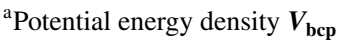

${ }^{\mathrm{b}}$ Energy density $\boldsymbol{H}_{\text {bcp }}$

${ }^{\mathrm{c}}$ Delocalization index DI 


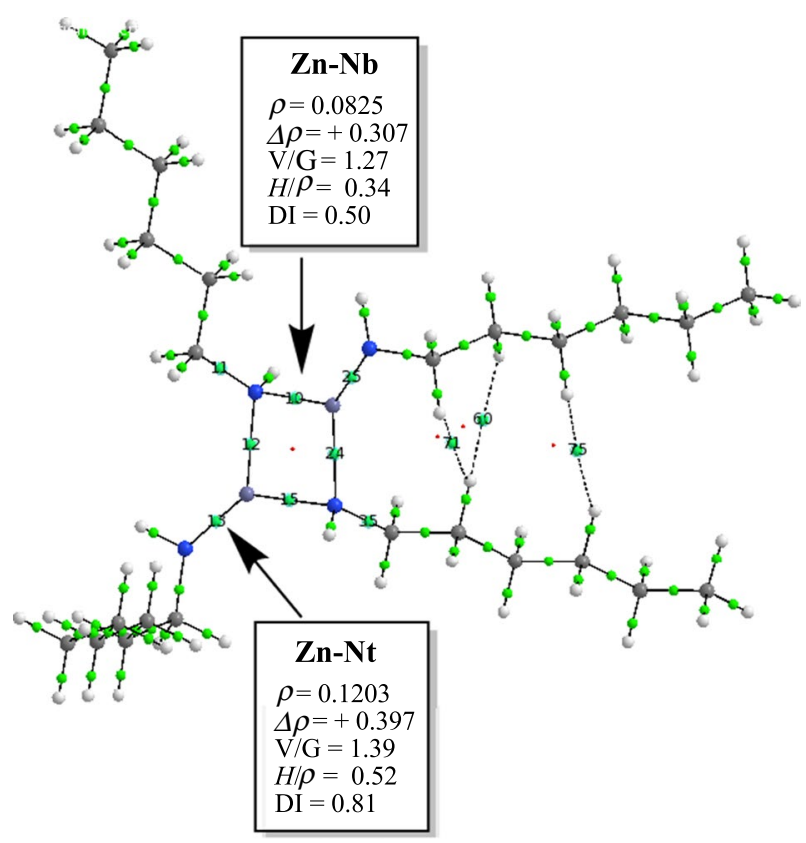

Fig. 4 QTAIM molecular graph of 3 calculated at the B3PW91/DGDZVP level. Bond critical points (BCPs) are located as small green spheres. Nitrogen atoms in blue spheres, zinc atoms in blue grey, carbon atoms in grey and hydrogen atoms in white colour. See main text and Table 1 for the definition of BCP descriptors. (Color figure online)

with dative bonds of strong covalence degree. A very similar QTAIM description was found for the $\mathrm{Ni}-\mathrm{C}$ phenylene bond in pincer complexes [20].

The $\left|V_{\text {bcp }}\right| / G_{\text {bcp }}$ ratio (1.27) of the four bridging $\mathrm{Zn}-\mathrm{Nb}$ bonds also refers to the intermediate bond regime. The weak electron density values ( $\rho_{\text {bcp }} \approx 0.08$ a.u.), large positive Laplacian values $\Delta \rho_{\text {bcp }}(0.310$ a.u.) and slightly negative energy densities $\boldsymbol{H}_{\text {bcp }}$, are in favour of a dative bond of strong ionic character (Table 1). Smaller values of DI (0.5) and $\left|\boldsymbol{H}_{\text {bcp }}\right| / \rho_{\text {bcp }}(0.34)$ suggest a weaker covalence degree of $\mathrm{Zn}-\mathrm{Nb}$ bonds as compared to the above $\mathrm{Zn}-\mathrm{Nt}$ bonds. In agreement with this strong covalence degree, the bond strength of terminal $\mathrm{Zn}-\mathrm{Nt}$ bonds appears to be about twice that of $\mathrm{Zn}-\mathrm{Nb}$ bridging bonds ( $E_{\text {int }}=70 \mathrm{kcal} \mathrm{mol}^{-1}$ vs. $42 \mathrm{kcal} \mathrm{mol}^{-1}$, respectively).

The ELF topological analysis of $\mathbf{3}$ is displayed in Fig. 5 and Table 2.

The terminal amido ligands are described by two disynaptic $\mathrm{V}(\mathrm{Zn}, \mathrm{Nt})$ ELF basins of inequivalent averaged populations ( 2.5 and $1.8 e$, respectively). The corresponding QTAIM atomic contributions of zinc to the $\mathrm{V}(\mathrm{Zn}, \mathrm{Nt})$ basin population are in the reverse order (7\% and $15 \%$, respectively). The $\mathrm{V}(\mathrm{Zn}, \mathrm{Nt})$ a attractor is located at about one-third of the $\mathrm{Zn}-\mathrm{Nt}$ bond distance, closer to $\mathrm{N}$ than to $\mathrm{Zn}$, while the other $\mathrm{V}(\mathrm{Zn}, \mathrm{Nt}) \mathrm{b}$ attractor is located at the top of the slightly trigonal pyramidal $\mathrm{N}$ atom (Fig. 5). A large covariance of these disynaptic basins with $\mathrm{C}(\mathrm{Zn})$ is calculated $\left(\left\langle\bar{\sigma}^{2}(\mathrm{~V}(\mathrm{Zn}, \mathrm{Nt}) i, \mathrm{C}(\mathrm{Zn}))\right\rangle=-0.16\right.$ and -0.19 for $i=a$ and $i=b$, respectively). In contrast to the above QTAIM analysis, the ELF description makes therefore a clear distinction between two components of the $\mathrm{Zn}-\mathrm{Nt}$ bond. 


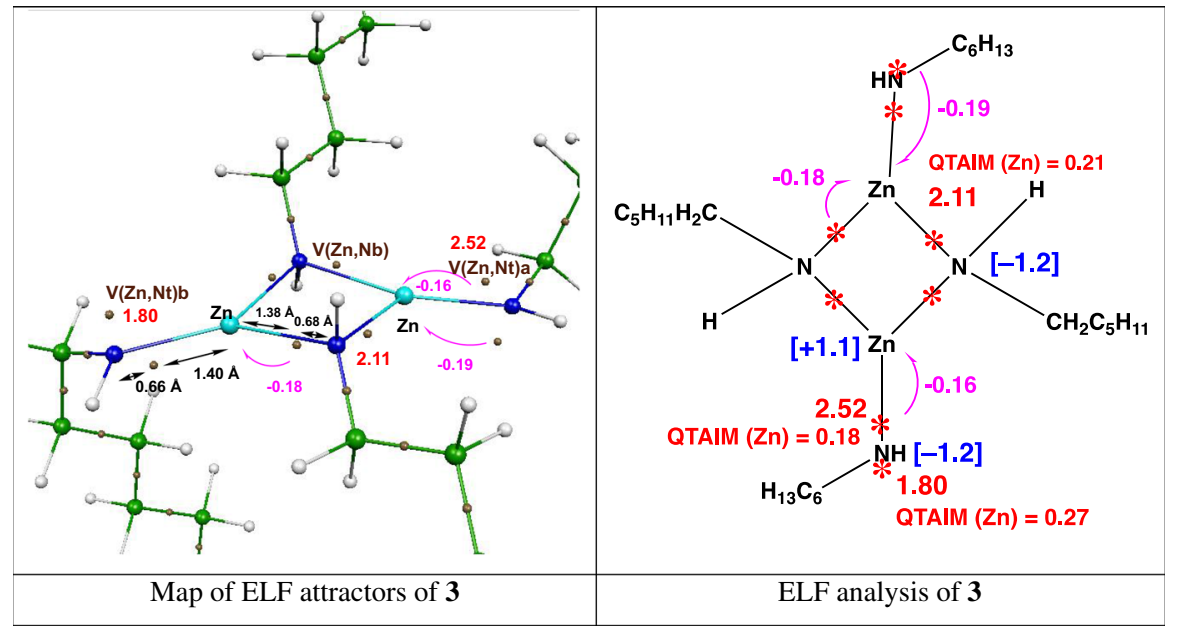

Fig. 5 ELF topological analysis of 3. Maps of ELF attractors (small brown spheres or red stars), displaying in red their average populations (in $e$ ), covariance values in magenta and selected QTAIM atomic charges in blue brackets (in $e$ ). Nitrogen atoms in blue spheres, zinc atoms in cyan, carbon atoms in green and hydrogen atoms in white colour. Descriptors are averaged over the four equivalent $\mathrm{Zn}-\mathrm{Nb}$ bonds and two quasi-equivalent $\mathrm{Zn}-\mathrm{Nt}$ bonds (see Table 2). B3PW91/DGDZVP level of calculation. (Color figure online)

Table 2 ELF descriptors of $\mathrm{Zn}-$ $\mathrm{Nt}$ and $\mathrm{Zn}-\mathrm{Nb}$ bonds in complex 3. B3PW91/DGDZVP level of calculation

\begin{tabular}{|c|c|c|c|}
\hline & \multicolumn{3}{|c|}{ ELF descriptors } \\
\hline & $\mathrm{V}(\mathrm{Zn}, \mathrm{N})^{\mathrm{a}}$ & $\% \mathrm{Zn}^{\mathrm{b}}$ & Cov. $^{\mathrm{c}}$ \\
\hline $\mathrm{Zn}-\mathrm{Nta}$ & 2.50 & $0.18(7.2 \%)$ & -0.16 \\
\hline $\mathrm{Zn}-\mathrm{Nta}$ & 2.55 & $0.18(7.1 \%)$ & -0.16 \\
\hline $\mathrm{Zn}-\mathrm{Ntb}$ & 1.83 & $0.27(14.8 \%)$ & -0.19 \\
\hline $\mathrm{Zn}-\mathrm{Ntb}$ & 1.78 & $0.28(15.7 \%)$ & -0.19 \\
\hline $\mathrm{Zn}-\mathrm{Nb}$ & 2.11 & $0.21(10.0 \%)$ & -0.18 \\
\hline $\mathrm{Zn}-\mathrm{Nb}$ & 2.11 & $0.22(10.0 \%)$ & -0.18 \\
\hline $\mathrm{Zn}-\mathrm{Nb}$ & 2.11 & $0.21(10.0 \%)$ & -0.17 \\
\hline $\mathrm{Zn}-\mathrm{Nb}$ & 2.11 & $0.21(10.0 \%)$ & -0.18 \\
\hline \multicolumn{4}{|c|}{$\begin{array}{l}\text { a Average population } \overline{\mathrm{N}} \text { of the ELF valence disynaptic basin } \mathrm{V}(\mathrm{Zn}, \mathrm{N}) \\
\text { (in } e \text { ) }\end{array}$} \\
\hline \multicolumn{4}{|c|}{${ }^{\mathrm{b}} \mathrm{QTAIM}$ atomic contribution of $\mathrm{Zn}$ to $\mathrm{V}(\mathrm{Zn}, \mathrm{N})$} \\
\hline \multicolumn{4}{|c|}{${ }^{\mathrm{c}}$ Covariance $\left\langle\bar{\sigma}^{2}(\mathrm{~V}(\mathrm{Zn}, \mathrm{N}), \mathrm{C}(\mathrm{Zn}))\right\rangle$} \\
\hline
\end{tabular}

The ELF descriptors of $\mathrm{V}(\mathrm{Zn}, \mathrm{Nt}) \mathrm{a}$ attractors are analogous to those previously reported for the $\mathrm{Cu}-\mathrm{N}$ dative bond in copper-imidazole complexes [21], or for the dative $\mathrm{Ag}-\mathrm{N}$ bond in silver-amidinate complexes [22] exhibiting a strong ionic character, suggesting a significant contribution of the zwitterionic mesomeric form $\mathrm{Zn}^{+}<-: \mathrm{N}:^{-}$. However, in contrast to these reported complexes, there is no remaining monosynaptic ELF V $(\mathrm{N})$ basin, which might be related to a lone pair of the nitrogen 
atom. In the ELF topological description of the parent $[\mathrm{NHR}]^{-}$amide anion, two monosynaptic $\mathrm{V}(\mathrm{N})$ basins, of average population of $2.13 e$, are indeed found beside the disynaptic $\mathrm{V}(\mathrm{N}, \mathrm{H})$ and $\mathrm{V}(\mathrm{N}, \mathrm{C})$ basins, the corresponding attractors being in a tetrahedral arrangement in agreement with the VSEPR (Valence Shell Electron Pair Repulsion) theory. Although the location of $\mathrm{V}(\mathrm{Zn}, \mathrm{Nt}) \mathrm{b}$ attractors would be consistent with such $\mathrm{V}(\mathrm{N})$ basins, both their large covariance with $\mathrm{C}(\mathrm{Zn})(-0.19)$ and their QTAIM atomic contributions of zinc (15\%) suggest that the second component of the $\mathrm{Zn}-\mathrm{Nt}$ bond is a also a dative bond but with a strong covalence degree, in agreement with the above QTAIM descriptors.

In contrast to $\mathrm{Zn}-\mathrm{Nt}$ bonds, the four bridging $\mathrm{Zn}-\mathrm{Nb}$ bonds are equivalent and each of them is described by only one disynaptic $\mathrm{V}(\mathrm{Zn}, \mathrm{Nb})$ ELF basin with a population of $2.11 e$ and a QTAIM atomic contribution of zinc of $10 \%$ (Table 2). The $\mathrm{V}(\mathrm{Zn}, \mathrm{Nb})$ attractor is located at about one-third of the $\mathrm{Zn}-\mathrm{Nb}$ bond distance, closer to $\mathrm{N}$ than to $\mathrm{Zn}$ (Fig. 5). All of these features along with their large covariance with $\mathrm{C}(\mathrm{Zn})\left(\left\langle\bar{\sigma}^{2}(\mathrm{~V}(\mathrm{Zn}, \mathrm{Nb}), \mathrm{C}(\mathrm{Zn}))\right\rangle=-0.18\right)$ are consistent with the presence of four equivalent $\mathrm{Zn}-\mathrm{Nb}$ dative bonds.

\section{ELF and QTAIM topological analyses of PAHVUP}

To the best of our knowledge, the Zn-amido bond was never investigated using ELF nor QTAIM topological analysis. Moreover, only one experimental structure featuring $\mathrm{Zn}$-amido bonds only could be extracted from the $\mathrm{CDB}$, namely the $\mathrm{Zn}$ \{ $\mathrm{N}[\mathrm{C}$ $\left.\left(\mathrm{CH}_{3}\right)_{3}\left(\mathrm{Si}\left(\mathrm{CH}_{3}\right)_{3}\right]\right\}_{2}$ complex referred to as PAHVUP [13]. It will be used hereafter as the reference for Zn-amido bonds. The ELF and QTAIM descriptors of PAHVUP are displayed in Fig. 6, Tables 3 and 4.

It is first noticeable that the QTAIM descriptors of both $\mathrm{Zn}-\mathrm{N}$ bonds of PAHVUP (Table 3), although little larger, are very close to those of $\mathrm{Zn}-\mathrm{Nt}$ bonds of complex $3\left(\left|\boldsymbol{V}_{\text {bcp }}\right| / \mathbf{G}_{\text {bcp }}=1.27, \mathrm{DI}=0.81,\left|\boldsymbol{H}_{\text {bcp }}\right| / \rho_{\text {bcp }}=0.50, \mathrm{E}_{\text {int }}=70 \mathrm{kcal} \mathrm{mol}^{-1}\right.$, see Table 1$)$. Similarly, the ELF description (Table 4) of both $\mathrm{Zn}-\mathrm{N}$ bonds of PAHVUP (equivalent via the $C$ s symmetry) is described by two disynaptic $\mathrm{V}(\mathrm{Zn}, \mathrm{N})$ basins as well as the $\mathrm{Zn}-\mathrm{Nt}$ bonds of complex $\mathbf{3}$. In contrast to $\mathbf{3}$, however, the corresponding attractors are both located at both sides and about one-third of the $\mathrm{Zn}-\mathrm{N}$ distance, closer to $\mathrm{N}$ than to $\mathrm{Zn}$, and the shift in their population or covariance is small. The only difference between both attractors is related to their QTAIM contribution of zinc, which is twice for the attractor with the weaker population (Table 4).

While the QTAIM description of $\mathrm{Zn}-\mathrm{Nt}$ in $\mathbf{3}$ or $\mathrm{Zn}-\mathrm{N}$ in PAHVUP refers to an almost fully covalent dative $\mathrm{Zn}-\mathrm{N}$ bond, the ELF topological analysis refers to a two-component dative bonding with various covalence degrees. Scheme 2 illustrates further this original description of the Zn-amido bond given by ELF topological analysis, involving electron delocalization in PAHVUP and three most representative mesomeric forms. As a consequence of the large cumulated scaled ELF populations of $\mathrm{V}(\mathrm{Zn}, \mathrm{N})$, namely $3.5 e$ (Scheme 2), a significant contribution of mesomeric forms exhibiting a $\mathrm{Zn}=\mathrm{N}$ (imino) double bond, involving both lone pairs of the parent $\left[\mathrm{N}^{t} \mathrm{Bu}\left(\mathrm{SiMe}_{3}\right)\right]^{-}$amide anion, is expected in PAHVUP. The same holds for complex 3. 


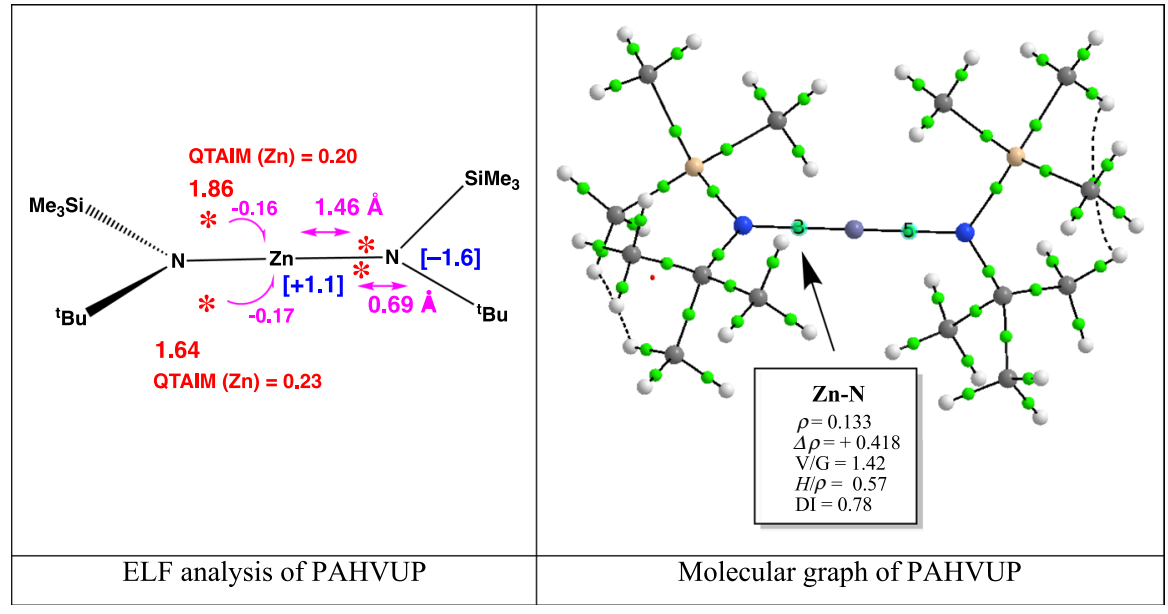

Fig. 6 (Left) Schematic map of ELF attractors (red stars), displaying in red their average populations (in $e$ ), covariance values in magenta and selected QTAIM atomic charges in blue brackets (in $e$ ). (Right) QTAIM molecular graph calculated for the experimental structure of PAHVUP. Bond critical points are located as small green spheres. Nitrogen atoms in blue spheres, zinc atom in blue grey, carbon atoms in grey and hydrogen atoms in white colour. See main text and Table 3 for the definition of BCP descriptors. B3PW91/DGDZVP level of calculation. (Color figure online)

Table 3 QTAIM descriptors (in a.u.) of the bond critical points (BCP) related to $\mathrm{Zn}-\mathrm{N}$ bonds in PAHVUP. B3PW91/DGDZVP level of calculation

\begin{tabular}{lllllllll}
\hline BCP & $\rho_{\text {bcp }}$ & $\Delta \rho_{\text {bcp }}$ & $V_{\text {bcp }}^{\mathrm{a}}$ & $H_{\text {bcp }}^{\mathrm{b}}$ & $\left|H_{\text {bcp }}\right| / \rho_{\text {bcp }}$ & $\left|V_{\text {bcp }}\right| / G_{\text {bcp }}$ & $\mathrm{DI}^{\mathrm{c}}$ & $E_{\text {int }}\left(\mathrm{kcal} \mathrm{mol}^{-1}\right)$ \\
\hline $\mathrm{Zn}-\mathrm{N}$ & 0.1339 & +0.418 & -0.25827 & -0.07692 & 0.57 & 1.42 & 0.78 & 81.03 \\
$\mathrm{Zn}-\mathrm{N}$ & 0.1372 & +0.426 & -0.26725 & -0.08041 & 0.59 & 1.43 & 0.79 & 83.85 \\
\hline
\end{tabular}

See BCP location and labelling in Figs. 4 and 5

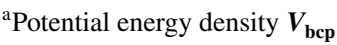

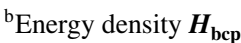

${ }^{\mathrm{c}}$ Delocalization index DI

Table 4 ELF descriptors of $\mathrm{Zn}-\mathrm{N}$ bonds in PAHVUP. B3PW91/DGDZVP level of calculation

\begin{tabular}{lll}
\hline ELF descriptors & & \\
\hline $\mathrm{V}(\mathrm{Zn}, \mathrm{N})^{\mathrm{a}}$ & $\% \mathrm{Zn}^{\mathrm{b}}$ & Cov. $^{\mathrm{c}}$ \\
\hline 1.86 & $0.20(10.8 \%)$ & -0.16 \\
1.64 & $0.23(25.0 \%)$ & -0.17 \\
\hline
\end{tabular}

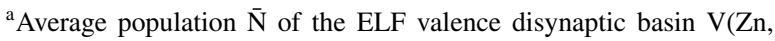
$\mathrm{N})$ (in $e$ )

${ }^{\mathrm{b}} \mathrm{QTAIM}$ atomic contribution of $\mathrm{Zn}$ to $\mathrm{V}(\mathrm{Zn}, \mathrm{N})$

${ }^{\mathrm{c}}$ Covariance $\left\langle\bar{\sigma}^{2}(\mathrm{~V}(\mathrm{Zn}, \mathrm{N}), \mathrm{C}(\mathrm{Zn}))\right\rangle$. According to the $C$ s symmetry of PAHVUP, the ELF descriptors of one couple of attractors only are disclosed 


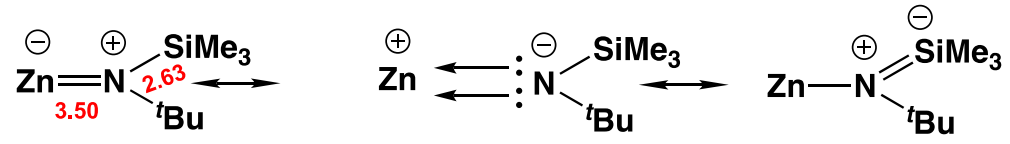

Scheme 2 Most representative mesomeric forms suggested from scaled ELF populations (in red) and covariance values $\left(\left\langle\bar{\sigma}^{2}(\mathrm{~V}(\mathrm{Zn}, \mathrm{N}), \mathrm{C}(\mathrm{Zn}))\right\rangle=-0.16\right.$ and $\left.\left\langle\bar{\sigma}^{2}(\mathrm{~V}(\mathrm{Zn}, \mathrm{N}), \mathrm{V}(\mathrm{N}, \mathrm{Si}))\right\rangle=-0.30\right)$

From their QTAIM and ELF pictures, Zn-Nt bonds of 3 appear therefore to be comparable but slightly weaker than the $\mathrm{Zn}-\mathrm{N}$ bonds of PAHVUP.

The ELF and QTAIM analysis of complexes $\mathbf{1}$ and $\mathbf{2}$, featuring one or two cyclohexyl extremities (Fig. 1), was then performed in order to study the influence of the termini on the bonding picture. The corresponding ELF and QTAIM descriptors are displayed in Fig. 7 and Table 5.

Zinc complexes 2 and 1 result, respectively, from the substitution of one or two $\mathrm{Zn}-\mathrm{Nt}$ bonds of $\mathbf{3}$ by $\mathrm{Zn}-\mathrm{Ccy}$ bonds. The ELF and QTAIM descriptors of the latter have therefore been compared to the ones of $\mathrm{Zn}-\mathrm{C}$ bonds in three references, namely $\mathrm{ZnEt}_{2}, \mathrm{Zncy}_{2}$ and CADCEP.

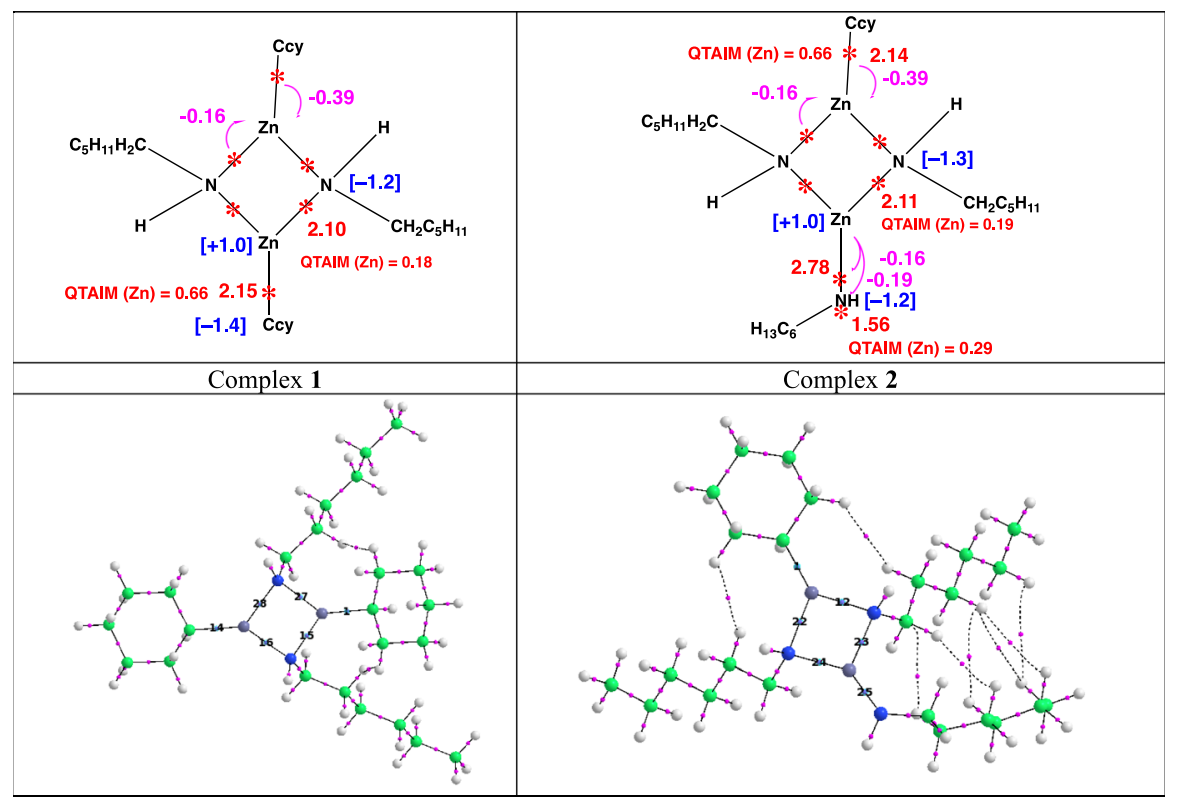

Fig. 7 (Top) ELF analysis of zinc complexes 1 and 2. Selected attractors are displayed as red stars and their average population values in red (in $e$ ); covariance values in magenta and selected QTAIM atomic charges in blue brackets (in $e$ ). Descriptors are averaged over the quasi-equivalent $\mathrm{Zn}-\mathrm{Nb}$ or $\mathrm{Zn}-\mathrm{Ccy}$ bonds. (Bottom) QTAIM molecular graphs of $\mathbf{1}$ and 2. BCPs are located as small magenta spheres. Nitrogen atoms in blue spheres, zinc atoms in grey, carbon atoms in green and hydrogen atoms in white colour. B3PW91/DGDZVP level of calculation. (Color figure online) 


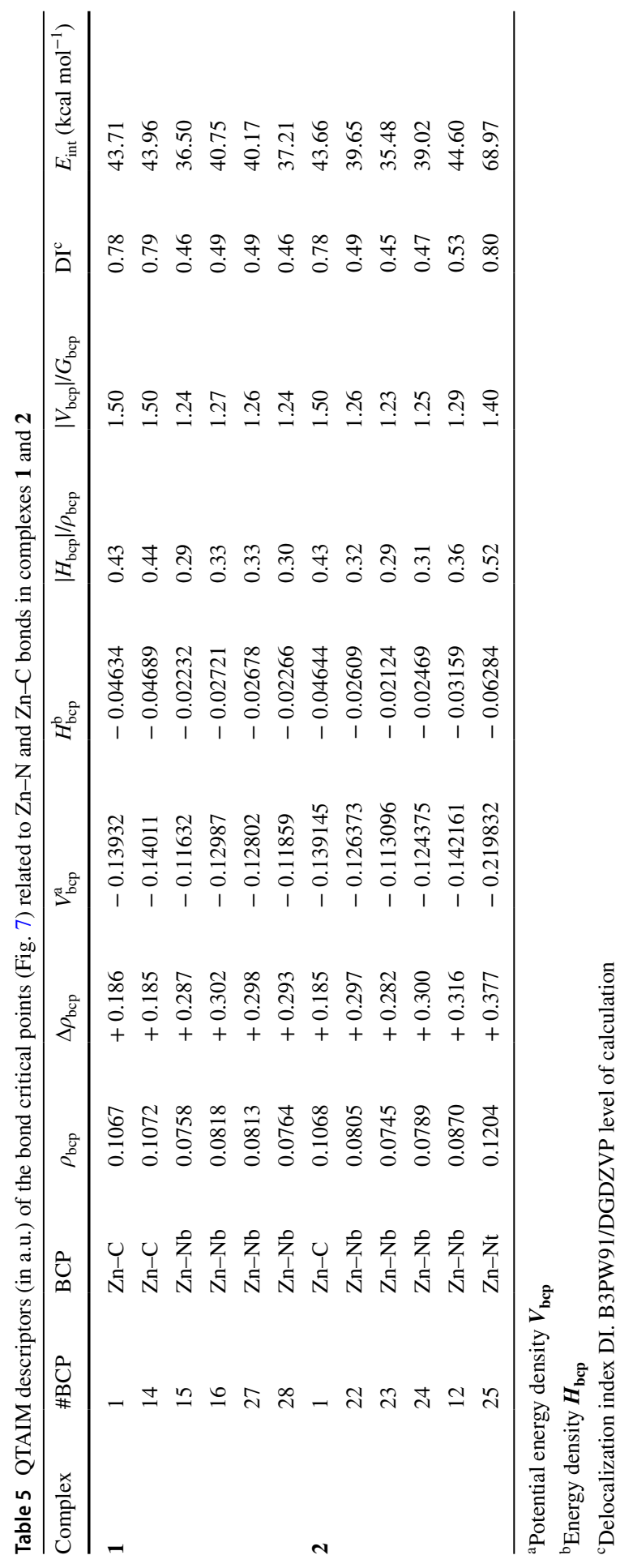


The ELF and QTAIM descriptions of $\mathbf{1}$ and CADCEP are very similar (Figs. 7 and 8). In order to further characterize their $\mathrm{Zn}-\mathrm{Ccy}$ bonds, they are compared hereafter to the topological analyses of $\mathrm{ZnEt}_{2}$ and $\mathrm{Zncy}_{2}$, displayed in Fig. 9.

The Zn-Ccy bonds of $\mathbf{1}$ and $\mathbf{2}$ and the Zn-Cmethyl (Zn-Me) bonds of CADCEP exhibit very similar ELF and QTAIM descriptors than those of $\mathrm{ZnEt}_{2}$ and $\mathrm{Zncy}_{2}$ (Figs. 7, 8 and 9). For all $\mathrm{Zn}-\mathrm{C}$ bonds in all five zinc complexes, the $\left|\boldsymbol{V}_{\mathbf{b c p}}\right| / \boldsymbol{G}_{\mathbf{b c p}}$ ratio $(\approx 1.50)$ refers to the intermediate bond regime between ionic and covalent bonds. The significant electron density values $\left(\rho_{\text {bcp }} \approx 0.11\right.$ a.u. $)$, large positive Laplacian values $\Delta \rho_{\text {bcp }}$ and negative energy densities at the BCP $\boldsymbol{H}_{\text {bcp }}$ are in favour of a dative bond (Figs. 7, 8 and 9; Table 5). Both DI (0.80-0.84 range) and $\left|\boldsymbol{H}_{\mathbf{b c p}}\right| / \rho_{\mathbf{b c p}}$ $(\approx 0.45)$ values suggest a significant covalence degree. According to these criteria, the QTAIM descriptors of the $\mathrm{Zn}-\mathrm{C}$ bonds are consistent with dative bonds of strong covalence degree, very similar to the QTAIM description of the first component of $\mathrm{Zn}-\mathrm{Nt}$ bonds of $\mathbf{3}$ and of the $\mathrm{Ni}-\mathrm{C}$ phenylene bond in pincer complexes [20]. This is further illustrated by the following representative mesomeric forms of equal weight describing diethyl- and dicyclohexylzinc complexes.

The QTAIM descriptors of the four quasi-equivalent $\mathrm{Zn}-\mathrm{Nb}$ bonds of 1, 2 and CADCEP $\left(\left|\boldsymbol{V}_{\text {bcp }}\right| / \boldsymbol{G}_{\text {bcp }}\right.$ ratio $\approx 1.25$, DI $(0.47)$ and $\left.\left|\boldsymbol{H}_{\text {bcp }}\right| / \boldsymbol{\rho}_{\text {bcp }}(\approx 0.33)\right)$ are slightly smaller than those of complex 3 (Fig. 5; Tables 1 and 2), suggesting a little weaker covalence degree of these dative bonds. This is also supported by their ELF population values (2.10 $e$ in $\mathbf{1}$ and $1.98 e$ in CADCEP vs. $2.11 e$ in 3). There is a very little influence of the extracyclic cyclohexyl termini on the bridging intracyclic $\mathrm{Zn}-\mathrm{Nb}$

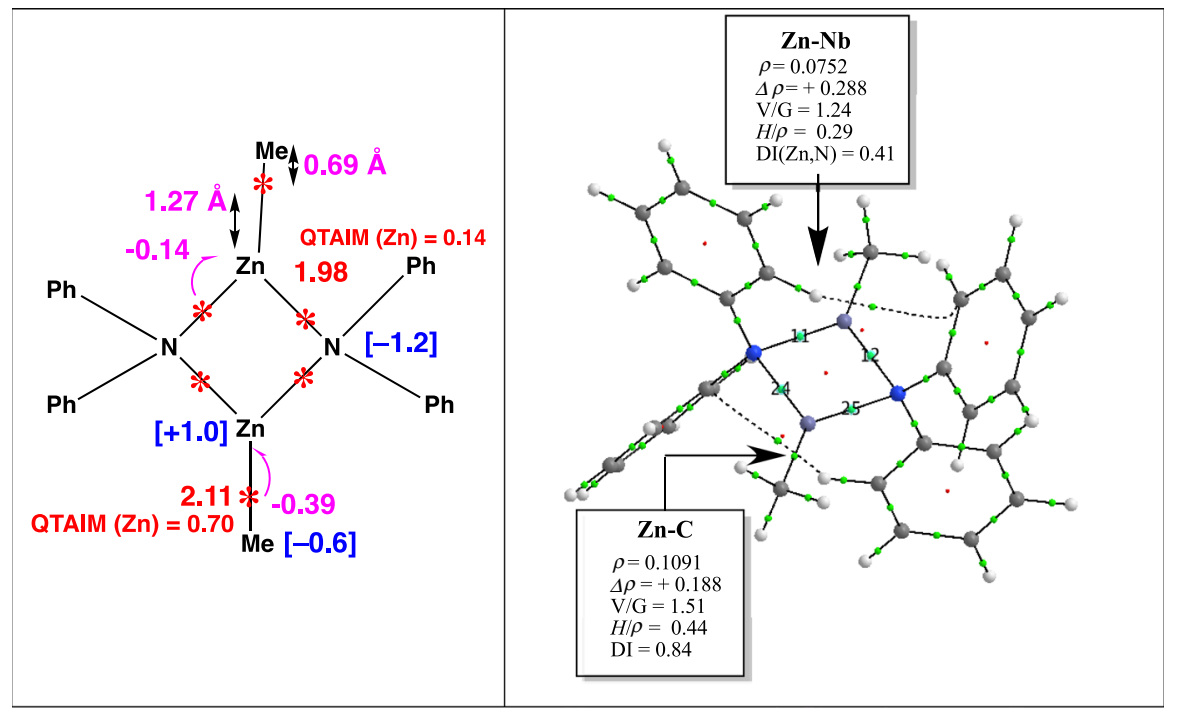

Fig. 8 (Left) Schematic map of ELF attractors (red stars), displaying in red their average populations (in $e$ ), covariance values in magenta and selected QTAIM atomic charges in blue brackets (in $e$ ). (Right) QTAIM molecular graph calculated for the experimental structure of CADCEP. BCPs are located as small green spheres. Nitrogen atoms in blue spheres, zinc atoms in blue grey, carbon atoms in grey and hydrogen atoms in white colour. B3PW91/DGDZVP level of calculation. (Color figure online) 
<smiles>CCCCCCCC</smiles>

$\mathrm{ZnEt}_{2}$

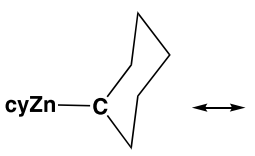

Zncy $_{2}$

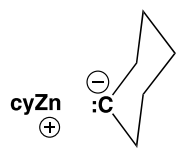

$\oplus$

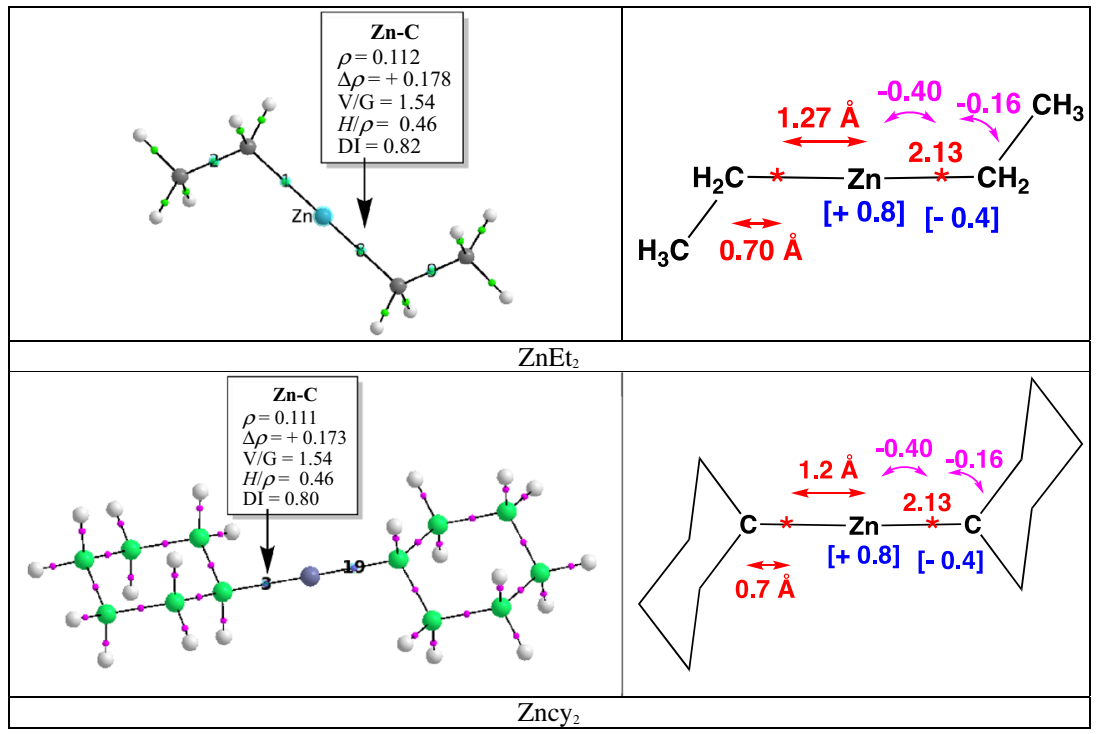

Fig. 9 (Left) QTAIM molecular graph calculated for $\mathrm{ZnEt}_{2}$ and $\mathrm{Zncy}_{2}$. Bond critical points are located as small magenta spheres, zinc atom in grey, carbon atoms in green and hydrogen atoms in white colour. (Right) Schematic map of selected ELF attractors (red stars), displaying in red their average populations (in $e$ ), covariance values in magenta and QTAIM atomic charges in blue brackets (in $e$ ). B3PW91/ DGDZVP level of calculation. (Color figure online)

bonds. The covalence degree of the $\mathrm{Zn}-\mathrm{Nb}$ bonds adjacent to the cyclohexyl extremity is slightly stronger.

\section{Chemical reactivity investigated from Fukui indices}

The chemical reactivity of the diamido-dicyclohexyl-dinuclear zinc complex 1, of two related complexes with one or two amido extremity ( $\mathbf{2}$ and $\mathbf{3}$, respectively) and of CADCEP was further investigated using Fukui functions $f^{-}$condensed on the ELF basins (Fig. 10).

The largest $f_{\mathrm{ELF}}^{-}$values are obtained for the ELF valence basins of the termini, namely both equivalent cyclohexyl (resp. methyl) termini in complex 1 (resp CADCEP) or both amido termini in complex 3 . In complex 2, the extracyclic Zn-amido extremity is the most sensitive to electrophilic attack. One dative component of the $\mathrm{Zn}-\mathrm{Nt}$ bond is more reactive than the other $\left(f^{-}(\mathrm{V}(\mathrm{Zn}, \mathrm{Nt}) \mathrm{a})=0.38>f^{-}(\mathrm{V}(\mathrm{Zn}, \mathrm{Nt}) \mathrm{b})=0.21\right)$, while the 


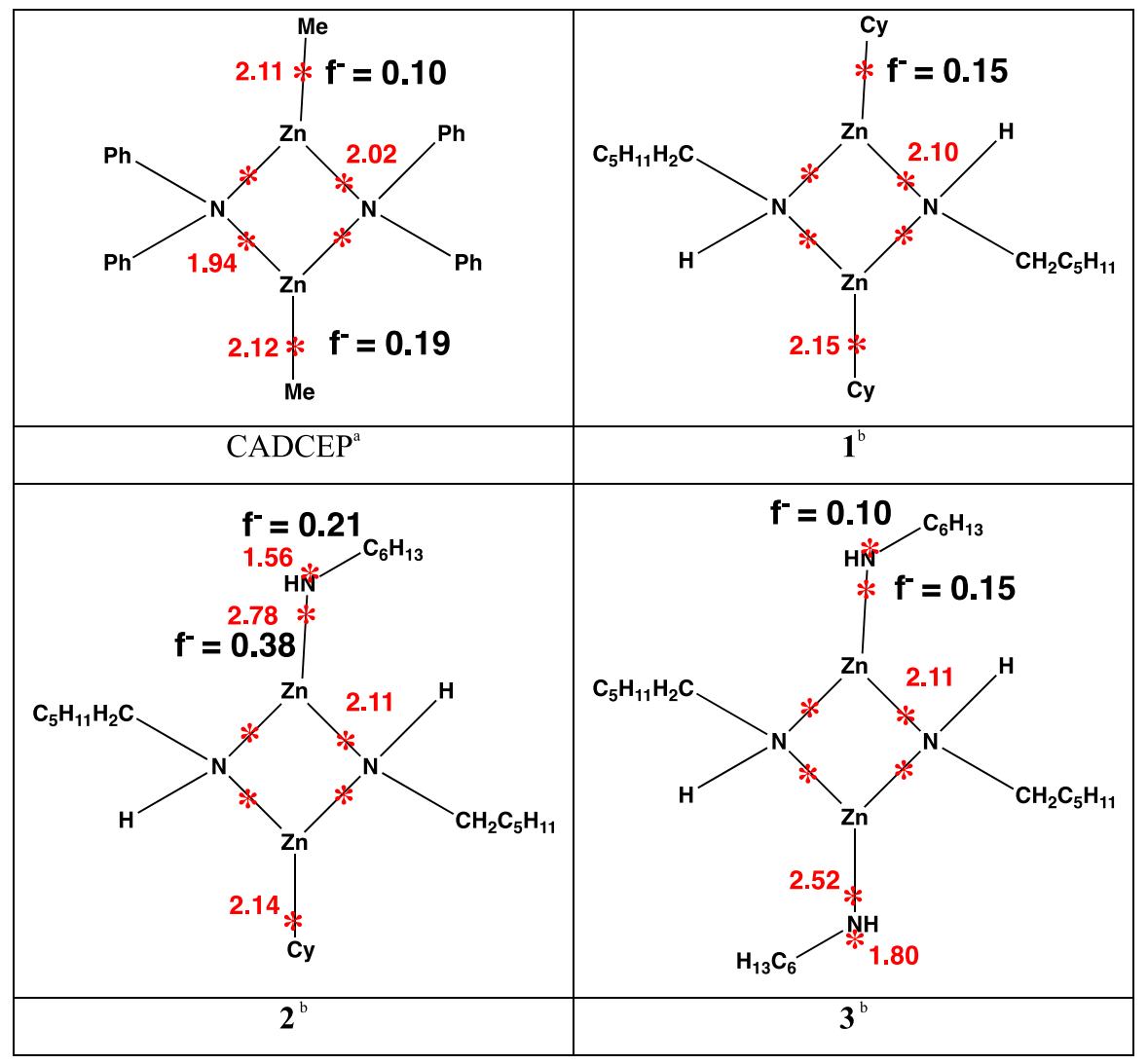

Fig. 10 Selected values of ELF populations (in red) and Fukui functions $f^{-}$condensed on ELF basins (in bold) for the complexes 1-3 and CADCEP extracted from the CDB (B3PW91/DGDZVP level of calculation). ${ }^{\mathrm{a}}$ Experimental geometry extracted from the CDB. ${ }^{\mathrm{b}}$ Geometries calculated at the PBE-D3/ DGDZVP level. (Color figure online)

cyclohexyl extremity exhibits no reactivity $\left(f^{-}(\mathrm{V}(\mathrm{Zn}, \mathrm{Ccy}))=0.0\right)$, suggesting that the former are the most reactive. In zinc complex 2 , where both the extracyclic cyclohexyl and amido extremities are present, the latter is the most reactive. Terminal zinc-amido bonds or zinc-alkyl bonds are therefore more reactive than the bridging $\mathrm{Zn}-\mathrm{Nb}$ bonds. This is consistent with an oligomerization pathway involving the propagation reaction via these terminal bonds and the cy-Zn-NHR intermediate $\left(\mathrm{R}=\mathrm{C}_{12} \mathrm{H}_{25}\right.$ for DDA or $\mathrm{R}=\mathrm{C}_{6} \mathrm{H}_{13}$ for the octylamine model) (Fig. 1, Eqs. 3 and 4). 


\section{Conclusions}

The intracyclic bridging $\mathrm{Zn}-\mathrm{Nb}$ bonds, the terminal zinc-amido ( $\mathrm{Zn}-\mathrm{Nt}$ ) and zinc-cyclohexyl (Zn-Ccy) bonds of three dinuclear zinc complexes 1-3 have been finely characterized using ELF and QTAIM topological analyses. To the best of our knowledge, the zinc-amido bond is studied here for the first time using topological analyses. The ELF picture of zinc-amido bonds refers to a two-component dative bonding with two different covalence degrees. Moreover, it may be described by a significant contribution of mesomeric forms exhibiting a $\mathrm{Zn}=\mathrm{N}$ double bond as illustrated for the experimental $\mathrm{Zn}\left\{\mathrm{N}\left[\mathrm{C}\left(\mathrm{CH}_{3}\right)_{3}\left(\mathrm{Si}\left(\mathrm{CH}_{3}\right)_{3}\right]\right\}_{2}\right.$ complex, referred to as PAHVUP in the CDB and used here as a representative of zinc-amido bonds.

Fukui indices condensed on the ELF basins allow for the comparison of the chemical reactivity of the three complexes. The larger sensitivity to electrophilic attack of the terminal zinc-amido bonds with respect to the bridging zinc-amido bonds or to the terminal zinc-cyclohexyl bonds is evidenced.

\section{Computational details}

Geometries were fully optimized at the PBE-D3/DGDZVP level of calculation using Gaussian09 [23]. Vibrational analysis was performed at the same level as the geometry optimization. Solvent effects of octylamine $(\varepsilon=3.1$ [24]) were included using the polarizable continuum model (PCM) implemented in Gaussian09. The influence of the length of the alkyl chain of the model amine of DDA was studied. No significant difference was found in the results using either hexylamine $\left(\mathrm{H}_{2} \mathrm{NC}_{6} \mathrm{H}_{13}\right)$ or octylamine $\left(\mathrm{H}_{2} \mathrm{NC}_{8} \mathrm{H}_{17}\right)$. The former was therefore selected in order to reduce the computational cost. However, octylamine was used as the solvent in PCM calculations, as its required dielectric constant was known.

Electron localization function (ELF) [5, 6] and topological analysis and quantum theory of atoms in molecules (QTAIM) $[3,4]$ analyses were performed with the TopMoD package [25]. ELF maps were plotted using the Molekel program [26]. QTAIM analysis was also performed with the AIMAll software [27].

\section{Topological analyses}

Topological methods are based on the analysis of the gradient field of a local function within the dynamic field theory and provide a partition of the molecular space into non-overlapping basins.

The topological analysis of the electron density $\rho(r)$, designed as the quantum theory of atoms in molecules (QTAIM) by R. Bader, yields atomic basins and QTAIM atomic charges [3, 4]. It allows defining bond paths and bond critical points (BCPs). The nature of the chemical bond is characterized from various properties of the electron density at the BCPs, especially the sign of the Laplacian of the electron density and the values of the kinetic energy density $\left(G_{\mathrm{bcp}}\right)$, of the potential energy density $\left(V_{\mathrm{bcp}}\right)$ and of the energy density $H_{\mathrm{bcp}}=G_{\mathrm{bcp}}+V_{\mathrm{bcp}}$, following the Bianchi's 
$[17,18]$ and Macchi's classification [19]. Negative and positive values for the Laplacian of the electron density at the $\mathrm{BCP}\left(\Delta \rho_{\mathrm{bcp}}\right)$ are assigned to «electron-shared» and «closed-shell» interactions, respectively [3,4]. Bianchi et al. [17, 18] distinguish three bonding regimes, depending on the value of the absolute ratio of the potential energy density to the kinetic energy density $\left(\left|V_{\text {bcp }}\right| / G_{\text {bcp }}\right)$. The intermediate bond regime $\left(1<\left|\boldsymbol{V}_{\mathbf{b c p}}\right| \boldsymbol{G}_{\mathbf{b c p}}<2\right)$ lies between electron-shared covalent bonds $\left(\left|\boldsymbol{V}_{\mathbf{b c p}}\right| / \boldsymbol{G}_{\mathbf{b c p}}\right.$ greater than 2) and closed-shell ionic bonds or van der Waals interactions $\left(\left|\boldsymbol{V}_{\mathbf{b c p}}\right| / \boldsymbol{G}_{\mathbf{b c p}}\right.$ lower than 1$)$ and includes dative bonds and ionic bonds of weak covalent character. The Macchi's classification relies on the values of both local descriptors and the delocalization index (DI) and offers a way to refine the bond characterization further. The covalence degree may be estimated from the latter and from $\left|H_{\mathrm{bcp}}\right| \rho_{\mathrm{bcp}}$ [18]. The strength of the interaction may be estimated from the correlation scheme of Espinosa et al. [28, 29] providing the corresponding positive interaction energy $\left(E_{\text {int }}=-1 / 2 V_{\text {bcp }}\right)$, with $E_{\text {int }}\left(\mathrm{kcal} \mathrm{mol}^{-1}\right)=-313.754 \times V_{\text {bcp }}(\mathrm{au})$.

The electron localization function (ELF) measures the excess of kinetic energy because of the Pauli repulsion [5, 6]. ELF values are confined between 0 and 1. ELF is close to 1 in regions where electrons are single or form antiparallel spin pairs, whereas it tends to 0 in regions where the probability to find parallel spin electrons close to one another is high [5, 6]. ELF tends to 1 in those regions where the electron localization is high (atomic shells, chemical bonds and lone electron pairs) [30], whereas it tends to small values at the boundaries between these regions [31]. The topological analysis of the ELF gradient field yields a partition of the molecular space into non-overlapping electronic domains, basins of attractors, classified into core, valence bonding and non-bonding basins. The attractors, namely local maxima of the ELF function, can be single points (general case), circles or spheres depending on the symmetry [7]. These basins are in one-to-one correspondence to the core, lone or shared pairs of the Lewis model. A core basin contains a nucleus $X$ (except a proton) and is designated as $C(X)$. A valence bonding basin lies between two or more core basins. Valence basins are further distinguished by their synaptic order, which is the number of core basins with which they share a common boundary. The monosynaptic basins denoted as $V(X)$ correspond to lone pairs, whereas the di- and polysynaptic ones are related to bi- or multi-centric bonds, denoted as $V(X 1, X 2$, $X 3 \ldots)$. The average population of the basin is obtained by integration of the oneelectron density over the basin volume. A statistical population analysis allows for considering the variance and the covariance of the basin populations, which are related to the electron delocalization [32]. The populations do not take integral values and are about twice the topologically defined Lewis bond orders for bonding valence basins $[32,33]$. The populations and (co)variances of these valence basins can be further interpreted in terms of weighted combinations of mesomeric structures $[32,33]$.

\section{Chemical reactivity descriptors}

The Fukui function was introduced by Parr and Yang as the response of the electron density of the molecular system to a change in the global number of electrons 
[10]. It can be expressed as the derivative of the electron density $\rho(\mathrm{r})$ with respect to the number of electrons $\mathrm{N}$ calculated at a constant external potential $v(r)$. Because of the discontinuity in this derivative, left and right derivatives have to be considered. The local Fukui functions $f^{+}(r)=(\partial \rho / \partial \mathrm{N})^{+} v$ and $f^{-}(r)=(\partial \rho / \partial \mathrm{N})^{-} v$ are therefore the response for adding or removing electrons from the system and allow for the investigation of nucleophilic and electrophilic attack, respectively. The finite difference approach $(\Delta N= \pm 1)$ allows for estimation of local Fukui functions $f(r)$ from the electron density $\rho(r)$ or of atomic Fukui indices $f(A)$ from atomic charges $Q(A)$ [34]:

$$
\begin{aligned}
& f^{+}(r)=\rho_{N+1}(r)-\rho_{N}(r) ; f^{-}(r)=\rho_{N}(r)-\rho_{N-1}(r) \\
& f^{+}(A)=Q_{N}(A)-Q_{N+1}(A) ; f^{-}(A)=Q_{N-1}(A)-Q_{N}(A)
\end{aligned}
$$

Alternative schemes involving frontier molecular orbital (FMO) Fukui functions (electron density approximated by densities of FMOs) condensed within an AIM [11] or ELF [12] topological partition have been disclosed. $f_{X}^{\alpha}(r)=\int_{X}\left|f_{\mathrm{KS}}^{F}(r)\right|^{2} \mathrm{~d} r$ is therefore the contribution of the FMO $F(\alpha=-: F=$ HOMO; $\alpha=+: F=$ LUMO) to the atomic AIM basin or to the core or valence ELF basin $X$. The latter descriptors are more attractive than the atomic indices of the finite difference approach, because they are confined in the 0 to 1 range and they sum up to one $\left(0 \leq f_{X}{ }^{\alpha} \leq 1\right.$ and $\left.\sum_{x} f_{X}{ }^{\alpha}=1\right)$. The larger the value of the $f$ index, the more reactive the corresponding basin $X$.

\section{Memories with Professor Michel Che}

Following a $\mathrm{PhD}$ under the direction of Professor Danièle Olivier in Laboratory of Reactivity and Surfaces (LRS) and a postdoctoral stay in Caltech in the group of Professor R. H. Grubbs, I joined the group of Professor Michel Che to work in the field of Coordination Chemistry at the Interface (ICC).

Following the advice of one member of my $\mathrm{PhD}$ committee, Professor JeanMarie Basset, I was encouraged by Professor Michel Che to implement molecular modelling in LRS within an experimental and theoretical chemistry interplay. Professor Michel Che initiated a collaboration with Professor Patrick Chaquin and Doctor Claude Giessner of the Laboratory of Theoretical Chemistry in University Paris VI. Then, he gave me a chance to be introduced to topological analyses and chemical bonding analysis. Professor Michel Che indeed asked me to represent him in a network about the development of VASP (Vienna Ab initio Simulation Package). There, I met Professor Bernard Silvi and Professor Andreas Savin of the Laboratory of Theoretical Chemistry (and topological analyses!) for the first time. It was the very first beginning of a long story of fun with electron localization function (ELF) topological analysis illustrated by the work reported in this article. Thanks again to Professor Michel Che. 
Acknowledgements The theoretical studies were performed using HPC resources from CALMIP (Grant 2019 [0851]]) and from GENCI-[CINES/IDRIS] (Grant 2019 [085008]). The authors wish to acknowledge the financial support of the Centre National de la Recherche Scientifique (CNRS).

\section{References}

1. M.L. Kahn, A. Glaria, C. Pages, M. Monge, L. Saint Macary, A. Maisonnat, B. Chaudret, J. Mater. Chem. 19, 4044 (2009)

2. Z. Zhao, Y. Coppel, J. Fitremann, P. Fau, C. Roux, C. Lepetit, P. Lecante, J.-D. Marty, C. Mingotaud, M.L. Kahn, Chem. Mater. 30, 8959 (2018)

3. R.F.W. Bader, in Atoms in Molecules (Clarendon Press, Oxford, 1990)

4. R.F.W. Bader, H. Essen, J. Chem. Phys. 80, 1943 (1984)

5. A.D. Becke, K.E. Edgecombe, J. Chem. Phys. 92, 5379 (1990)

6. B. Silvi, A. Savin. Nature 371, 683 (1994)

7. B. Silvi, I. Fourré, M.E. Alikhani, Monatsh. Chem. 136, 855 (2005)

8. C. Lepetit, P. Fau, K. Fajerwerg, M.L. Kahn, B. Silvi, Coord. Chem. Rev. 345, 150 (2017)

9. B. de Courcy, L.G. Pedersen, O. Parisel, N. Gresh, B. Silvi, J. Pilmé, J.P. Piquemal, J. Chem. Theory Comput. 6, 1048 (2010)

10. R.G. Parr, W. Yang, J. Am. Chem. Soc. 106, 4049 (1984)

11. F.A. Bulat, E. Chamorro, P. Fuentealba, A. Toro-Labbé, J. Phys. Chem. 108, 342 (2004)

12. W. Tiznado, E. Chamorro, R. Contreras, P. Fuentealba, J. Phys. Chem. 109, 3220 (2005)

13. W.S. Rees Jr., D.M. Green, W. Hesse, Polyhedron 11, 1697 (1992)

14. N.A. Bell, H.M.M. Shearer, C.B. Spencer, Acta Crystallogr. Sect. C: Cryst. Struct. Commun. 39, 1182 (1983)

15. A.D. Pajerski, G.L. BergStresser, M. Parvez, H.G. Richey Jr., J. Am. Chem. Soc. 110, 4844 (1988)

16. J. Krahmer, R. Beckhaus, W. Saak, D. Hasse, Z. Anorg. Allg. Chem. 634, 1696 (2008)

17. R. Bianchi, G. Gervasio, D. Marabello, Inorg. Chem. 39, 2360 (2000)

18. E. Espinosa, I. Alkorta, J. Elguero, E. Molins, J. Chem. Phys. 117, 5529 (2002)

19. P. Macchi, D.M. Proserpio, A. Sironi, J. Am. Chem. Soc. 120, 13429 (1998)

20. C. Lepetit, B. Vabre, Y. Canac, M.E. Alikhani, D. Zargarian, Theor. Chem. Acc. 137, 141 (2018)

21. M. Boukallaba, B. Kerkeni, C. Lepetit, D. Berthomieu, J. Mol. Model. 22, 301 (2016)

22. M. Puyo, E. Lebon, L. Vendier, M.L. Kahn, P. Fau, K. Fajerwerg, C. Lepetit, Inorg. Chem. 59, 4328 (2020)

23. M.J. Frisch, G.W. Trucks, H.B. Schlegel, G.E. Scuseria, M.A. Robb, J.R. Cheeseman, G. Scalmani, V. Barone, B. Mennucci, G.A. Petersson, H. Nakatsuji, M. Caricato, X. Li, H.P. Hratchian, A.F. Izmaylov, J. Bloino, G. Zheng, J.L. Sonnenberg, M. Hada, M. Ehara, K. Toyota, R. Fukuda, J. Hasegawa, M. Ishida, T. Nakajima, Y. Honda, O. Kitao, H. Nakai, T. Vreven, J.A. Montgomery Jr., J.E. Peralta, F. Ogliaro, M. Bearpark, J.J. Heyd, E. Brothers, K.N. Kudin, V.N. Staroverov, R. Kobayashi, J. Normand, K. Raghavachari, A. Rendell, J.C. Burant, S.S. Iyengar, J. Tomasi, M. Cossi, N. Rega, J.M. Millam, M. Klene, J.E. Knox, J.B. Cross, V. Bakken, C. Adamo, J. Jaramillo, R. Gomperts, R.E. Stratmann, O. Yazyev, A.J. Austin, R. Cammi, C. Pomelli, J.W. Ochterski, R.L. Martin, K. Morokuma, V.G. Zakrzewski, G.A. Voth, P. Salvador, J.J. Dannenberg, S. Dapprich, A.D. Daniels, Ö. Farkas, J.B. Foresman, J.V. Ortiz, J. Cioslowski, D.J. Fox, Gaussian 09, Revision D.01 (Gaussian Inc, Wallingford, 2009)

24. P.-M. Chassaing, F. Demangeot, V. Paillard, A. Zwick, N. Combe, Phys. Rev. B 77, 153306 (2008)

25. S. Noury, X. Krokidis, F. Fuster, B. Silvi, Comput. Chem. 23, 597 (1999)

26. Molekel 4.3 from CSCS: http://www.cscs.ch/molekel/

27. T.A. Keith, AIMAll (Version 17.11.04), TK Gristmill Software, Overland Park KS, USA, aim. tkgristmill.com

28. E. Espinosa, E. Molins, C. Lecomte, Chem. Phys. Lett. 285, 170 (1998)

29. E. Espinosa, I. Alkorta, I. Rozas, J. Elguero, E. Molins, Chem. Phys. Lett. 336, 457 (2001)

30. J. Poater, M. Duran, M. Sola, B. Silvi, Chem. Rev. 105, 3911 (2005)

31. B. Silvi, R.J. Gillespie, C. Gatti, Compr. Inorgan. Chem. II 9, 187 (2013)

32. B. Silvi, Phys. Chem. Chem. Phys. 6, 256 (2004)

33. C. Lepetit, B. Silvi, R. Chauvin, J. Phys. Chem. A 107, 464 (2003)

34. H. Chermette, P. Boulet, S. Portmann, Rev. Mod. Quant. Chem. 2, 992 (2002) 